Trab. Ling. Aplic., Campinas, 43 (2): 249-264, Jul./Dez. 2004

\title{
PROCESSO DISCURSIVO E SUBJETIVIDADE NA AVALIAÇÃO EM LE (INGLÊS) NO ENSINO UNIVERSITÁRIO. ${ }^{1}$
}

\author{
MARALICE S. NEVES
}

(UFMG)

\begin{abstract}
In this paper I discuss some representations of oral evaluation in the learning of English as a Foreign Language (FL) in a Brazilian undergraduate institution for FL teachers. My analysis includes questions and concepts from applied linguistics, discourse analysis and psychoanalysis. In this perspective, subjectivity is constituent of discourse; subject-teachers take contradictory positions during the assessment of their students' learning process. These positions are characterized as gestures of interpretation because they answer demands, in this case, from scientific, technical, juridical and political/transferencial voices. The corpus was constructed with discursive practices of teachers and students at the end of a 4 year-course of study. In my analysis, I use the concept of Discursive Formations (DF), understood as enunciative regularities within a field of knowledge. I take as themes the elements of traditional oral evaluation, such as fluency and pronunciation, and representations of communicative competence/proficiency. As a result, I show that, in the process of assessment, people take stands within DFs that I have named "Including" and "Excluding", as well as some of its modulations, "Unconditional inclusion", and "Excluding perfection". The "Excluding" DF is characterized by the representation of perfection which contradictorily excludes both the students' fault and excellence. The "Inclusive" DF accepts the student's faults and progress, turning relative their performance. In this DF a progress and a passing grade above an abstract minimum are guaranteed to all or most students.
\end{abstract}

Keysworld: evaluation, subjectivity, dicourse.

\section{INTRODUÇÃO}

Este trabalho apresenta uma visão antipositivista do discurso da avaliação de aprendizagem de uma língua estrangeira (inglês) produzido por alunos e professores de uma universidade pública do estado de Minas Gerais. Essa visão tem como pressuposto teórico a perspectiva transdisciplinar de Serrani-Infante (1998) que retoma questões da Lingüística Aplicada e as problematiza no cruzamento de noções e conceitos da Análise do Discurso da vertente francesa apresentada por Pêcheux $(1990,1995)$ com conceitos da psicanálise, conforme propostas de Freud (1909-1910) e Lacan (1985, 1985b, 1998).

A questão que procuro examinar parte do caráter contraditório do ato de avaliar que é geralmente rejeitado e desconsiderado por muitos professores, ao mesmo tempo em que

${ }^{1}$ Texto resultante da Tese de Doutorado "Processo discursivo e subjetividade: vozes preponderantes na avaliação da oralidade em língua estrangeira no ensino universitário" apresentada ao Curso de Lingüística Aplicada - Ensino/Aprendizagem de LE/SL - do Instituto de Estudos da Linguagem, Unicamp, defendida em 2002, sob a orientação da Prof. Dra. Silvana Mabel Serrani. 
NEVES - Processo discursivo e subjetividade...

é valorizado como instrumento de alto poder e status conforme atestado por Scaramucci, (1998) em pesquisa sobre o efeito retroativo do vestibular. É comum ouvirmos nos depoimentos de professores queixas em relação ao conflito gerado por suas decisões que oscilam de modo instável entre atos considerados impressionistas, injustos, altamente subjetivos e atos referendados pelos lingüistas aplicados como criteriosos, objetivos e informados segundo as novas teorias sobre linguagem. Estes buscam, então, respostas e soluções na "objetividade do saber científico, mito da verdade que legitima a ciência", como afirma Coracini (2003, p. 109).

Busco compreender o que é exatamente da ordem da subjetividade, ou seja, algo que escapa ao fato de estar informado e que invade o espaço de uma não-intenção nos atos de avaliação da aprendizagem de nosso aluno. Nessa concepção de subjetividade, o sujeito não é entendido como uno, centrado e intencional, mas cindido, heterogêneo, incapaz de se definir como uno, a não ser na dimensão das representações imaginárias enquanto $e u$ (ego), na busca do desejo de outros sujeitos. Somos sujeitos da/na linguagem e interpretamos sentidos advindos de nossa história, de nossas relações sociais, da ideologia, de um inconsciente desejante.

Ao interpretar, tomamos posições prenhes de contradições, pois estas estão no âmbito do imaginário (através das imagens, da percepção de indivíduo, em suas lutas de poder), do simbólico (nível da linguagem) e do real (não visto como realidade, mas como o contingente, o indizível, um resto, o algo que falha, que falta e que se apresenta em forma de lapsos, de equívocos, algo que aponta para o desejo do sujeito). A tomada da palavra acontece no discurso através de processos identificatórios e transferenciais entre os falantes e essa subjetividade não é de todo apreendida no discurso e nos procedimentos formais da avaliação.

Portanto, na segunda parte, apresento a visão discursiva da aprendizagem de línguas na qual concebo, a partir de Serrani-Infante (1998), a interdependência entre materialidade lingüística e processo discursivo operando na produção/compreensão em segunda língua. $\mathrm{Na}$ terceira e na quarta partes apresento um breve panorama de algumas noções e conceitos da vertente teórica da AD que, ao permitir uma interface com conceitos da psicanálise, me possibilitou analisar os vários discursos que estão em jogo na tomada de posição de professores e alunos em relação à fluência, à pronúncia e à competência comunicativa na produção oral em LE, elementos das representações que eles têm da LE, seu ensino, aprendizagem e avaliação. Desenvolvo a noção de Formação Discursiva (FD) bem como as categorias de análise que me possibilitaram chegar a duas formações discursivas e duas modulações depreendidas de depoimentos e práticas de sala de aula.

\section{UMA VISÃO DISCURSIVA DE ENSINO/APRENDIZAGEM E DAAVALIAÇÃO DE LÍNGUAS}

Ao conceber o sujeito como efeito de sentido, passei a entender o processo de aprendizagem de uma LE como enunciação em segunda língua e o seu desenvolvimento como modos de acontecimento. A língua não é representada somente como código (que é explícito), mas também como estrutura verbal simbólica realizada em processos discursivos, historicamente determinados e determinantes na constituição do sujeito (Serrani-Infante, 1997). Operando com o conceito de Formações Discursivas (doravante FD) enquanto condensações de regularidades enunciativas, há um momento na aprendizagem da LE no qual aparece de modo mais evidente a operação lingüístico-discursiva de nominação. A 
processualidade do dizer (Pêcheux \& Fuchs, 1990; Orlandi, 1996) e suas não coincidências (Authier, 1984, 1998) fazem-nos compreender que nomear é uma operação prenhe de mediações. E essa mediação é uma operação de predicação (designação de um conceito e discurso sobre o valor atribuído a esse conceito). Essa predicação é um sistema de valores, e devemos entendê-lo como FDs, pois elas determinam o que se pode e o que não se pode dizer.

Parto, portanto, do pressuposto de que há uma interdependência entre materialidade lingüística (da ordem do sistema da língua) e processo discursivo operando na produção/ compreensão em segunda língua (Serrani-Infante, op.cit.). Ou seja, o sistema da língua só se realiza em processos discursivos, compostos por FDs. Tanto a materialidade (a língua como instrumento) quanto o processo operam em duas dimensões: na dimensão da intencionalidade representada nos enunciados dos interlocutores e na dimensão da subjetividade inconsciente juntamente com as determinações sócio-históricas (ideológicas). É esta última que em grande parte determina o sucesso ou o insucesso da produção na LE, pois sofre a mediação imaginária aliada à dimensão simbólica. Quando fala, o sujeito representa tudo ao seu redor e se representa por imagens construídas na cadeia lingüísticodiscursiva. A tomada de posição enunciativa é a tomada da palavra (tanto na língua materna quanto na LE). Esta diz respeito a relações de poder e processos identificatórios.

Ao tomarem a palavra, os falantes jogam com as vozes dos outros, o sujeito tem que se deixar falar, enunciar, mesmo quando monologa, porque o corpo também é discurso. Essas outras vozes que falam em nós são daqueles que tiveram e têm participação de algum modo em nossa formação, através de gestos, de textos (orais ou escritos), da memória discursiva (do que é herdado, de valores e estereótipos), polifonia no sentido baktiniano (Coracini, 1998). Isto implica em identificações imaginárias mobilizadas pelo aluno/falante. Se ele está mobilizado, desejará significar, exprimir sua realidade de sujeito, produzir sentido. O que se mostra através da língua, que é simbólica, faz parte do imaginário do sujeito. E o que está sempre em questão é o agenciamento de significantes. O falar põe em questão a inserção do significante no real ${ }^{2}$, e o real não é da ordem da realidade ${ }^{3}$ (imaginária), mas da ordem do impossível, indizível. A ordem do imaginário opera todo o tempo: o sujeito deseja coisas inefáveis, impossíveis, mas se mobiliza para consegui-las.

Não é possível controlar todas as questões que entram em jogo no momento da produção de linguagem, como desejam muitos criadores de materiais didáticos ou mentores

\footnotetext{
${ }^{2}$ No discurso, o real é um limite posto pelo real da língua e pelo real da história (esta tem uma materialidade e não outra). Tudo está em movimento contínuo. No jogo entre a formulação e a constituição do dizer e dos sentidos, que produz o efeito de exterioridade, o sentido-lá, está o real. O real, para Orlandi, (1998b:21) é "função das determinações históricas que constituem as condições de produção materiais.

${ }^{3}$ Vale pontuar aqui a reformulação lacaniana da questão da realidade. Reinterpretando o texto de Freud, Mais Além do Princípio do Prazer, Lacan (1985) propõe que o princípio do prazer é que cesse o prazer, e como o princípio de realidade opera respondendo ao princípio do prazer, a função deste último consiste em fazer com que o jogo dure, ou seja, que o prazer se renove, que seja resguardado, já que o prazer tende a cessar. Por fim, resume Castelo Branco (1995: 48), "a pulsão de morte opera para regular os outros dois princípios em direção ao recomeço deste jogo". Castelo Branco aponta que a formulação das relações entre princípio do prazer, princípio de realidade e pulsão de morte põem em xeque a noção de realidade que se refere ao mundo exterior (mundo objetivo) ou ao mundo construído pela experiência (entendimento). A noção de realidade em Lacan só pode ser compreendida à luz do aparelho psíquico. É considerada como contingente e plural; arranjos da linguagem, mundos sociais onde a linguagem vige, diversas configurações subjetivas que entram em cena na construção de um mundo, dentro dos vários mundos possíveis. "Cada realidade se funda e se define de um discurso" e "o ser da realidade, em sua multiplicidade, depende, sobretudo, das formas de vida e dos discursos que o condicionam e o delimitam", resume Castelo Branco (p.50-1) citando Lacan.
} 
de métodos revolucionários, professores/ avaliadores e até mesmo alunos. Sabemos também que não é um processo linear, nem processo de assimilação de regras, acúmulo de léxico ou sequiências de situações comunicativas que se pode armazenar e utilizar no momento oportuno. O sujeito recebe o significante do exterior e este é matéria prima do inconsciente (Lacan, 1966/1998). Não obstante, o desejo do controle (no caso, da produção lingüística) é cultural, pautado pela crença positivista, racionalista, afirma Coracini (1995).

A área avaliação em Lingüística Aplicada ao ensino de línguas estrangeiras (LE) abarca uma bibliografia ampla cujo discurso é consoante com as discussões em Educação em geral. Especificamente no Brasil, os Parâmetros Curriculares Nacionais (PCN) das línguas estrangeiras $(1997,1998)$ trazem o conceito de avaliação interativo, dialógico ${ }^{4}$, discurso no qual o aluno deve participar das decisões no planejamento e avaliação em negociação com o professor. Essa demanda vem reforçar o discurso de especialistas em avaliação de aprendizagem que propõem um movimento de mudança da avaliação através, quase que exclusivamente, de provas (julgamento de um produto) para procedimentos que abarcam observações em sala de aula, diários dialógicos, auto-avaliações e portfolios ${ }^{5}$ de alunos (julgamento do processo). Nessa proposta, os instrumentos devem todos ser elaborados baseados em informações sobre estilos e estratégias de aprendizagem ${ }^{6}$ e sobre o desenvolvimento da autonomia do aluno ${ }^{7}$, dentre outros estudos. A proposta é que haja um bom treinamento em técnicas de produção de instrumentos e definição de critérios claramente explicitados e rigorosos para que alcancemos a desejada objetividade numa multiplicidade de mecanismos sistematizados de forma a garantir a transparência dos atos de avaliação. Acredita-se que, ao estar devidamente informado sobre os conceitos, os procedimentos e as atitudes que deve tomar, o professor estará, então, preparado para as mudanças atuais necessárias na cultura de ensinar e avaliar em educação de LE.

No entanto, esse controle através de processos de avaliação, ilusoriamente claros e transparentes, acontece no nível da materialidade da língua - no intradiscurso, separada do processo discursivo - o interdiscurso, dimensão não linear, vertical do discurso que fornece a matéria-prima para a constituição do sujeito (Pêcheux, 1990). É por esta razão que desejei compreender os atos de avaliação dos protagonistas desta pesquisa, procurando, com a minha análise, "atravessar o efeito de transparência da linguagem, da literalidade do sentido e da onipotência do sujeito” (Orlandi, 1999:61), uma vez que não há como não remeter à rede complexa de FDs em que todo dizer está inserido.

\footnotetext{
${ }^{4}$ Conceitos baseados em Bakhtin (1979) e Vigotsky (1987), dentre outros.

${ }^{5}$ Sobre o uso de portfolio, conduzi uma pesquisa que resultou na monografia intitulada "O portfolio na aprendizagem de língua estrangeira”, desenvolvida para o Curso de Especialização em Avaliação a Distância UNB - Faculdade de Educação e Cátedra Unesco de Educação a Distância, iniciado em 1997 e concluído em 1998 (não publicada). Ver, também O’Malley \& Pierce (1996); Herman et al. (1992) e Genesee \& Upshur (1996).

${ }^{6}$ Ver, por exemplo, Oxford (1990), Reid (1995), O’Malley \& Chamot (1990).

${ }^{7}$ Por exemplo, ver em Dickinson (1987) e Nunan (1989).
} 
Trab.Ling.Aplic., Campinas, 43 (2) - Jul./Dez. 2004

\section{ALGUMAS NOÇÕES DA AD E SUAS CATEGORIAS DE ANÁLISE}

Segundo Pêcheux (1995), Pêcheux \& Fuchs, (1990) e Orlandi, (1999), uma FD é hoje entendida como redes de memória e filiações histórico-discursivas de identificação, heterogêneas, contraditórias e de fronteiras fluidas e que Serrani-Infante (2001:47) reelabora como "condensações de regularidades enunciativas em processos constitutivamente heterogêneos e contraditórios de produção de sentidos em diferentes domínios do saber". Nessa noção, articulam-se as formações ideológicas que regulam, sob a pretensa 'transparência da linguagem' o que se torna hábito e uso, mascarando o caráter material do sentido e das palavras. E são as FDs que representam na linguagem as formações ideológicas que lhe são correspondentes. Os sentidos são constituídos nas FDs e mudam de sentido ao passarem de uma FD a outra. Não há como caracterizar fronteiras das formações ideológicas e discursivas, mas há como pensar nos sentidos que se realizam nos efeitos de paráfrase, formações de sinônimos, substituições que constroem representações preponderantes nas formulações dos enunciadores através de metáforas e metonímias, sempre através da interpretação ( Orlandi, 1998a).

Desse modo, busco compreender as FDs que regulam as tomadas de posição dos sujeitos envolvidos no domínio do saber da avaliação da oralidade em LE no Curso de Letras de uma instituição pública de Minas Gerais. Centrei-me nos dois últimos semestres do curso de inglês porque queria observar os acontecimentos de avaliação em classes nas quais os sujeitos estivessem em condições de tomar posições 'autorizadas' na produção oral da LE.

Como categorias de análise, utilizei-me da noção de interpretação como lugar onde o sentido sempre deriva para outro (Pêcheux, 1990; Orlandi, 1998a); da noção de ressonância discursiva, na qual "determinadas marcas lingüísticas se repetem para construir a representação de um sentido predominante" (Serrani-Infante, 2001:47) e da noção de contradição (Foucault, 1997), uma vez que esta funciona no fio do discurso como o princípio de sua historicidade, no interdiscurso. Na análise do corpus, a interpretação é o espaço no qual trabalha a $\mathrm{AD}$, porque não há sentido sem interpretação e, portanto, não há literalidade, mas o espaço da metáfora e da metonímia, ou seja, o lugar onde o sentido desliza para tornar-se outro, lugar de manifestação do inconsciente, da ideologia, na constituição dos sujeitos e na produção de sentidos (Orlandi, 1998), efeito de uma relação significante (Lacan, 1998).

Pensando-se a paráfrase como repetições que fazem discurso (Courtine, 1981) dentro de uma noção de polifonia da linguagem que pode acampar diversos níveis de análise semântica (Bakhtin, 1992, Ducrot, 1987, Authier, 1998), concebo com Serrani-Infante (op.cit.) que o enunciado possui um sentido particular e, simultaneamente, são possíveis outras interpretações, as quais, por sua vez, podem coincidir de algum modo com as de outros enunciados. A noção de FD é que encampa as regularidades das ressonâncias com referência à construção das representações de sentidos predominantes nas práticas discursivas da avaliação. Examinam-se, na análise (Serrani-Infante, 2001:40), por exemplo:

a) itens lexicais de uma mesma família de palavras ou itens de diferentes raízes lexicais apresentados no discurso como semanticamente equivalentes. 
b) construções que funcionam parafrasticamente.

c) modos de enunciar, presentes no discurso (tais como o modo determinado e o modo indeterminado de enunciar; o modo de definir por negações, ou por afirmações modalizadas ou categóricas, modo de acréscimos contingentes através das incisas, glosas etc.)

O corpus deste estudo foi organizado com depoimentos abertos ${ }^{8}$ de cinco professores e dezesseis alunos, diários de classe e escritos de alunos participantes das avaliações em sala de aula sobre acontecimentos de avaliação da oralidade em LE. Os depoimentos abertos (Serrani-Infante, 1999) foram produzidos de modo que os enunciadores gravaram em áudio respostas a perguntas abertas, estando eles preferencialmente sozinhos e instruídos a não se preocuparem com repetições, lapsos, contradições. Nesse procedimento, o objetivo da análise não está no seu conteúdo informacional, mas nas marcas lingüísticas que apontam para regularidades enunciativas ou momentos de interpretação em atos de tomadas de decisão. Outras seqüências utilizadas são de registros de aulas e correspondência eletrônica trocada entre a pesquisadora e os professores.

\section{ALGUNS FOCOS DE ANÁLISE}

Em primeiro lugar, procurei levantar representações com referência ao que se entende por proficiência na LE. Várias seqüências dos depoimentos abertos se condensam para reforçar posicionamentos em relação a dois elementos fortes ligados ao que se avalia da oralidade, a fluência e a pronúncia. Esses posicionamentos ressoam tanto no discurso da ciência, ou seja, dos especialistas em ensino e avaliação de LE (discurso caracterizado como prescritivo) quanto no discurso dos professores e alunos sujeitos desse corpus.

Em seguida, mostro algumas condensações de sentidos no entrecruzamento de diferentes domínios do discurso, os quais nomeio científico, técnico, jurídico e político/ transferencial e que serão mais bem explicitados adiante. Essas condensações de sentido são responsáveis pelas tomadas de posição de nossos protagonistas.

Por fim, apresento a caracterização de duas FDs e suas modulações no campo da avaliação em LE, entendendo-as como configurações discursivas que regulam os atos de avaliação dos professores nas condições de produção analisadas.

\subsection{Representações sobre a fluência e a pronúncia no discurso de alunos e professores}

Para depreender representações acerca desses elementos, primeiro em relação à fluência, utilizei seqüências tanto de alunos quanto de professores que funcionam parafrasticamente para se condensarem em sentidos que podem ser exemplificados nas

\footnotetext{
${ }^{8}$ Procedimento do projeto AREDA (Análise de ressonâncias discursivas em depoimentos abertos) desenvolvido por Serrani-Infante e publicado em vários artigos, dentre eles, "Discurso e Aquisição de Segundas Línguas" (texto produzido em 1996 e publicado em 1999) e "Abordagem Transdisciplinar na enunciação em segunda língua: a proposta AREDA" (1998).
} 
seqüências abaixo (em 9 alunos e 3 professores). Nelas, fluência significa facilidade para falar, falar bem, falar como um nativo, transmitir tudo o que se quer, falar com naturalidade e espontaneidade. Estes sentidos apontam para o desejo de possuir uma língua que, ao ser natural e espontânea, torna-se ideal, padronizada e perfeita e, dessa forma, possuída somente pelo nativo.

1) ${ }^{9}$ ( )quando você é fluente você consegue/ tem a capacidade de se comunicar com facilidade e entender com facilidade também as coisas que estão sendo ditas/ principalmente quando está sendo dito por um native speakerl [Clarice, aluna]

2) eu acho que fluência é você falar com clareza elter rapidez de pensamento na hora de se comunicar.(...) [Mozart, aluno]

3) (..) é//eu acredito que sou fluente na língua/ tenho uma capacidade pra me expressar dentro do ritmo dessa língua/ né/ também/ então/ não só pronúncia mas também ritmo e entonação// eu já passei por testes e nesses testes eu sou considerada native-like// e meus amigos me consideram uma/uma boa, é/consideram que minha competência é boa ou muito boa () eu mesma me considero bilíngüe em português, inglês, quer dizer, agora, inclusive/ trilíngüe espanhol/ eu falo estas três línguas como eu falo a minha língua materna [Tatiana, professora]

No entanto, abaixo, vemos um outro posicionamento, na fala de outros alunos e professores, que aceita melhor a contingência de estrangeiro, que dá alguma tranqüilidade em relação ao que o autoriza como falante estrangeiro, que pode se aceitar (e ser aceito) como tal.

4) é uma consciência de uma parte que eu sei/ uma consciência de que eu tenho um conhecimento pelo menos razoável da estrutura da língua inglesa/ me/ essa consciência me dá uma/ alguma tranqüilidade [Ana, professora]

5) (..) é/ eu acho que a partir do momento que eu consigo conversar com meus amigos em inglês, eles me entendem e eu também os entendo/ eu acho que o desempenho é satisfatório (...) o aprendiz bem sucedido de língua/ é aquele que consegue entender e ser entendido/né/ e consegue assimilar através da linguagem um pouco da cultura daquela/l língua [Carol, aluna]

Em relação à pronúncia, os sentidos se condensam para formar também representações de uma concepção do nativo como ‘dono' da LE exposto no exemplo da aluna abaixo:

6) se eu acho que a pronúncia do inglês é importante?/ é muito importante/ não só do inglês como de qualquer outra língua/eu gosto muito do/do inglês britânico/ eu acho/é pu/

\footnotetext{
${ }^{9}$ Nas transcrições aqui reproduzidas, os parênteses significam cortes meus de partes que se repetem para não deixar que o enunciado fique longo demais. As partes realçadas em itálico são as que ressoam parafrasticamente. Todas as transcrições estão à disposição dos leitores na sala 18 do pavilhão de departamentos do IEL-UNICAMP ou na sala 4036 da FALE-UFMG. Ver também em Neves (2002).
} 
NEVES - Processo discursivo e subjetividade...

pura preferência/ eu/ eu gosto do inglês britânico/ eu acho/ mais elegante (...) ah/eu acho que o principal/ no meu caso o principal é a pronúncia (...) eu acho que- que um dos elementos é/ essa imersão na cultura (...) eu não sou nativa/ então eu sempre vou falar/de uma maneira/ com sotaque/ ou/é lógico/ isso é lógico/ mas a tendência da gente é sempre achar que a gente é inferior na/ na pronúncia/ mesmo porque a gente não é nativo/ [Clara, aluna]

Dentre os 16 enunciadores-alunos a importância da pronúncia boa, correta, clara, inteligível, certa, próxima do nativo, ressoa para 12 deles (75\%) como fundamental para a compreensão e comunicação. Os outros alunos deram maior importância à entonação, mas em geral também voltaram seu desejo para a posse de uma pronúncia ou entonação que se aproximasse ao máximo à do nativo. Vale ressaltar os sentidos que reverberam semanticamente para um ideal abstrato, imaginado por cada um a partir das representações de si, da língua (ou de suas partes) e do outro (o professor, o pesquisador, o nativo, etc.).

Por outro lado, vemos, abaixo, o posicionamento de um professor que relativiza o que se espera do falar dos alunos sobre uma pronúncia que não seja a do nativo como referência, natural, perfeita, 'ideal'. Desse modo, ele mostra uma maior tolerância às imperfeições e valorizando-as no dizer: curva entonacional (...) agradável aos ouvidos dos falantes nativos. Esses sentidos são também parafrásticos a alguma tranqüilidade, um conhecimento razoável, consciência de uma parte que sabe, aceitação da diferença, o lugar onde um brasileiro pode chegar.

7) eu acho que nós devemos caminhar pro Brazilian English/então na medida que você elitiza que você só aceita/éluma característica americana ou britânica ou/ excepcionalmente/ australiana de inglês/ eu acho que vocêlélfavorece as pessoas/ aquelas que tiveram capacidade de viajar ou meios financeiros/ (...) a nossa curva entonacional/ acho que é agradável aos ouvidos dos falantes nativos/ pelo menos os/com os quais eu convivil [Pedro, professor]

Cabe, ainda, apontar que alguns alunos falam de uma posição 'autorizada', o que quer dizer que se sentem à vontade com sua pronúncia e podem até falar do lugar de professor por se encontrarem já nesta posição empírica, enquanto professores de institutos particulares ou estagiários do Centro de Extensão. Já outros alunos falam de uma posição menos autorizada por não se encontrarem no nível idealizado por si próprios (no qual o Outro interior fala) e pelo outro (o professor, o nativo etc.). No entanto, como também podemos observar nas seqüências dos professores, os sentidos deslizam mostrando o conflito de identificações entre o que se deseja - falar como um nativo ideal - e o que se espera falar ao menos como um estrangeiro inteligível (com pronúncia boa, que se entenda bem).

\subsection{Condensação de sentidos no entrecruzamento de diferentes domínios do discurso}

Posicionamentos como os acima apontados, que nos levam a dois tipos de condensação de sentidos diferenciados, influenciam as tomadas de posição tanto dos professores quanto dos alunos no jogo de imagens que fazem da LE, de sua própria enunciação na LE e na 
enunciação que esperam dos outros, nativos e não-nativos. Esses posicionamentos são parte importante nos atos dos protagonistas em relação à avaliação de aprendizagem da LE. Portanto, durante a análise, ao enfocar a gestão da avaliação da proficiência ou competência comunicativa, depreendi, nas seqüências dos enunciadores, vozes advindas de diferentes domínios do discurso. Portanto, nas representações e nos gestos dos enunciadores, fazem efeito sentidos dos domínios técnico, científico, jurídico e político/ transferencial.

A voz dos domínios da ciência e da técnica é depreendida nos dizeres dos protagonistas (professores e alunos) nos modos deônticos de enunciar que naturalizam o que esses sujeitos percebem no discurso da Educação, da Lingüística Aplicada e dos especialistas em avaliação pertencentes a estes campos de conhecimento. Várias seqüências analisadas contêm enunciados do tipo: tem que interagir com o aluno, tem que ser uma situação mais realista, a entrevista não pode ser uma conversa informal, tem que avaliar o conteúdo estudado e tem que centralizar nos objetivos do aluno. Abaixo, podemos ver um exemplo de uma das seqüências:

8. eu/acho que deve haver também uma/ uma certa estrutura nas entrevistas/ né/ As entrevistas não podem ser uma conversa informal/ né// ela deve buscar/ é / elementos/ né/ na fala do/do candidato que você está sendo avaliado/é/buscar elementos que evidenciem/ né/ o nível de proficiêncial é/de quem tá sendo avaliado/ [Tatiana, professora]

Em relação ao discurso jurídico (depreendido dos atos em sala de aula), a autoridade institucional de avaliar, formalmente conferida aos professores, é, muitas vezes, atribuída ao aluno (através da avaliação pelos pares, por exemplo), causando equívocos e conflitos em relação à troca de lugares ou posições dos alunos entre si e com seus professores, uma vez que no discurso entende-se que não se pode falar do lugar do outro (Orlandi, 1998). O exemplo a seguir mostra o conflito de compreensão do professor em relação aos atos de avaliação de seus alunos:

9. Um grupo de 4 alunas, particularmente ruins, deu as piores notas para um aluno excelente. Será que era inveja, será que era incapacidade de entender e portanto de avaliar? [Professor X, correspondência eletrônica]

Neste gesto das alunas, no modo como é descrito, parece fazer efeito também a ideologia da excelência, na qual o falar 'perfeito' do nativo é o exemplo para marcar o erro do colega. Ao mesmo tempo, o professor as representa como incapazes de chegar a algum ideal de falante. O sentimento perturbador da inveja conferida pelo professor às alunas é uma projeção sua do valor moral que ele lhes dá: o da impossibilidade de conseguirem a excelência do aluno competente (que a rigor só cometeu um pequeno erro), uma vez que o que se inveja são os bens e a maneira como gozam os outros (Prasse,1997). Ao aluno proficiente, o professor projeta o gozo de saber bem a língua; às alunas fracas, a inveja desse gozo (ou o gozo da inveja).

Em relação ao que chamo de domínio político/transferencial, o ato político de organização e direção da conduta nas relações dos sujeitos não se dá somente no nível da 
NEVES - Processo discursivo e subjetividade...

intenção, mas, predominantemente, no nível inconsciente. Segundo Freud (1910-1969) ${ }^{10}$, "a transferência surge espontaneamente em todas as relações (...) é ela, em geral, o verdadeiro veículo da ação terapêutica”, mas como na relação professor-aluno ela não é caracterizada como veículo da ação terapêutica. Ela pode ser considerada uma metáfora da transferência (Riolfi, 1999), caso o Sujeito Suposto Saber ${ }^{11}$ (Lacan, 1985b) dito do analista seja tomado no professor e este, ao agenciar o elo social com o aluno, pode reproduzir saberes, alienandoos ou propiciando a separação do saber do aluno.

Nos atos aqui considerados, há um acionamento dos mecanismos de afeto, confissão e resistência por parte dos alunos (no nível imaginário da identificação, por exemplo, com algum traço de professores magnânimos ou carrascos, se imaginamos os extremos) caracterizados nos pedidos de ajuda, confissão de fracassos e reclamações, a serem ou não atendidos pelos professores, como podemos ver nos dizeres dos alunos condensados abaixo:

10. Afeto (o professor tem que...): descontrair os alunos; tentar dar dicas; tentar ajudar; não inibir; proporcionar o ambiente; estar atento à personalidade do aluno, conhecer o aluno; reconhecer o monitoramento do erro (pelo aluno). Confissão (os alunos são prejudicados porque...): lado emocional pode atrapalhar; o aluno tem as suas dificuldades; há aluno tímido, inibido, acanhado; introvertido; errar e (poder) corrigir o erro. Resistência (do aluno em relação aos atos de avaliação do professor): não cobrar algo muito difícil ou temas específicos, avaliar o aluno na informalidade, provas são mal necessário, avaliar até certo nível, evolução nas provas e testes (foi) pequena.

São as demandas dos alunos, as exigências das instituições, os dizeres proferidos pela ciência e pela técnica e as representações simbólicas e imaginárias dos professores sobre a LE em confronto com as representações dos alunos, que configuram tomadas de posição dos professores, muitas vezes, instáveis e contraditórias. As reações do sujeitoprofessor ao erro do aluno são determinadas não só pelas representações de língua suas e dos alunos, mas também pelo elo que o professor estabelece (ou não) com o aluno. Finalmente, estes gestos se condensam em algumas regularidades enunciativas que podem ser apreendidas em FDs.

\subsection{Caracterização de duas Formações Discursivas e suas modulações no domínio da avaliação em LE: configurações que regulam os atos de avaliação}

Ao falarem sobre a avaliação oral na sala de aula, os protagonistas assumem posições de acordo com a(s) discursividade(s) que melhor traduzem os seus momentos de identificação imaginária e simbólica. Desse modo, não há como pensar numa identidade

\footnotetext{
${ }^{10}$ Citação retirada da edição eletrônica brasileira no texto Quinta Lição nas Cinco Lições de Psicanálise (v. 11).

${ }^{11}$ Função que funda a transferência, cada vez que alguém se encarna para um sujeito como localizável. O Sujeito suposto saber se refere ao analista, pois ele é suposto saber a significação daquilo que o sujeito demanda, uma vez que este é sujeito do desejo. O eu, ao falar, depende de que um outro leia o que ele não consegue escutar de sua fala (Lacan, 1985b).
} 
Trab.Ling.Aplic., Campinas, 43 (2) - Jul./Dez. 2004

acabada, formada, mas sim postular momentos de identificação, em movimento constante e em constante modificação (Serrani-Infante, 1997b; Coracini, 1998). Num discurso ilusoriamente uno, vemos que oscilam ora convicções da ordem da ciência, ora de ordem técnica, ora (e principalmente) de ordem político/transferencial. São gestos, que instáveis em suas determinações, se manifestam em falas e atos geralmente contraditórios. Nos três mecanismos que apontei - afeto, confissão e resistência - percebo-os como momentos onde o Eu se mostra. Neles, os elos sociais (entre professores e alunos) se estabelecem a partir de processos identificatórios entre os protagonistas e os referentes (a língua, a avaliação) e vão se fazendo observar em pedidos, queixas, dádivas, recusas, exigências, enfim, de tudo o que perpassa o processo institucionalizado de aprendizagem da língua.

No entanto, considero que se delineiam dois modos de ouvir ou não essas vozes vindas do âmbito político/transferencial. Um modo sugere ser aquele de não ouvir as demandas dos alunos, ou seja, quando os dizeres da técnica e da ciência se sobrepõem ao elo afetivo entre o professor e o aluno. Nesses dizeres, o aluno é representado como uma abstração assim como os instrumentos para controlá-lo. Enquanto isso, o olhar para o aluno-enunciador, ali presente, fica obscurecido. $\mathrm{O}$ outro modo parece ser o de privilegiar a demanda do aluno, talvez a despeito do tempo jurídico (o tempo de aprender estabelecido pela instituição) ou das vozes da ciência e da técnica (pressupostas no conhecimento que o professor deve ter sobre avaliação).

Além dos depoimentos, analisei também os acontecimentos de avaliação oral em sala de aula. Dos gestos de interpretação de dois professores observados, Pedro e Tatiana, apreendemos duas FDs, a FD Excludente e a FD Inclusiva.

\subsubsection{A FD Excludente}

A seqüência abaixo apresenta sentidos que convergem para uma preocupação com aspectos técnicos, dizeres da ciência e da técnica sob a ideologia da excelência. Porém, os mesmos dizeres são desestabilizados por aspectos políticos e transferenciais de afeto, contradição fundamental ao construto de objetividade técnica.

11. (...) a avaliação do desempenho oral/ por exemplo/ ela é subjetiva por natureza/ visto que o avaliador é sempre um indivíduo/ então/ né/ quer dizer/ o indivíduo tem que ser treinado para evitar que/é/critérios/é/não/critérios/às vezes não objetivos interfiram na sua avaliação.(...) se o desempenho daquele aluno/ né/ naquele momento não condizer com o que o professor conhece/ o justo seria que o professor adequasse o resultado da sua avaliação ao que conhece do aluno e não àquele momento/ é/então também/ você dizer ao aluno que ele se saiu mal numa proval quando você sabe que no cotidiano ele se desempenha muito bem/ então isso eu não acho que também seja justo porque a avaliação tem que ser um retrato daquilo que o outro faz no cotidiano e se o retrato não condiz/ tem que tirar uma outra foto.[Tatiana, professora]

No entanto, veremos em seguida que, no momento da tomada de posição dessa professora em relação ao julgamento das notas, diferentemente do que afirma no depoimento acima, ela se insere na FD Excludente. Nesta FD, são excluídas as demandas dos alunos 
NEVES - Processo discursivo e subjetividade...

(ou aquilo que se conhece deles) em favor de um valor simbólico subjetivo representado como perfeição.

Cabe assinalar, no que considero uma modulação da FD Excludente, que Tatiana identifica-se com a posição de uma exigência de desempenho que, embora desejado como perfeito, não pode acontecer. A contradição se mostra no enunciado abaixo, feito à pesquisadora para explicar as notas dadas aos alunos, nas quais foram feitos comentários qualitativos para fundamentar a quantificação de cada nota desta avaliação oral (dentre o total de 3 eventos de avaliação do curso como um todo: uma através de portfolio, outra através de um projeto escrito e a última através de uma apresentação oral do projeto). Ela explica porque descartou a retirada de pontos dos alunos que não compareceram à apresentação do colega, segundo o que exigira deles.

12. Quanto aos pontos nas apresentações: na realidade eu só usei do argumento ponto como fator de pressão pra que os alunos não faltassem. Ou seja, não tirei ponto de ninguém por não ter vindo à apresentação do colega. De qualquer maneira seu comentário de que ninguém tirou nota máxima é correto: I don't believe in perfect e uma nota máxima é dizer que está perfeito - o que naquela turma ninguém foi...[Tatiana, correspondência eletrônica]

O ato de tirar pontos é abandonado devido, provavelmente, ao conflito que surge do seu imaginário de perfeição e as vozes oriundas do domínio técnico, e dos domínios político e jurídico. Há, portanto, um conflito entre a neutralidade e objetividade técnicas e o ato de justiça em relação ao que ela exigiu e o que o aluno cumpriu. Nesse último caso, a retirada de pontos somente pela ausência do aluno caracterizaria um ato (jurídico) de injustiça ${ }^{12}$. Daí, então, a opção considerada mais justa: fala a voz da neutralidade e da objetividade técnicas da avaliação, representadas nos critérios já propostos e que legitimam os atos políticos da professora.

Esse gesto da professora configuraria, portanto, a modulação da FD que nomeei Perfeição Excludente. Nela, os bons alunos nunca atingem a nota máxima, o zero-defeito, a perfeição. No corpus de arquivo apresentado pela professora, todas as notas foram quantificadas com comentários qualitativos a respeito da sua performance, tais como: excellent presentation, good presentation, not very clear presentation, used Portuguese in final presentation, good command of English but not a very clear presentation, good presentation but problems with expression and pronunciation. Contudo, nenhuma nota máxima foi conferida, mesmo para o aluno cujo comentário foi o de excellent presentation.

\subsubsection{A FD Inclusiva}

Na FD Inclusiva, preponderam as demandas dos alunos a despeito do discurso da ciência e da técnica e da ideologia da excelência. No discurso do professor Pedro, por exemplo, reverberam dizeres do domínio político/transferencial, como ilustrado na seqüência abaixo:

\footnotetext{
${ }^{12} \mathrm{~A}$ pesquisadora observou que na sala de aula que vários alunos faltaram à apresentação dos colegas.
} 
13. (...) Já fiz uma pré-avaliação: dentro de uma unidade que tinha o tema de "laughter is the best therapy" (que teve seu clímax quando tivemos uma sessão onde todos puderam rir uns dos outros, guiados por instruções em inglês), eles trabalharam um texto sobre a técnica do riso em grupo. Ao final, pedi para se prepararem em casa de modo a poderem ler em voz alta um parágrafo do texto escolhido ao acaso. ( ) $\mathrm{Na}$ aula seguinte, enquanto todos faziam uma atividade escrita, chamei um por um para uma sala ao lado, e eles puderam ler seu parágrafo para um gravador, repetindo a leitura quando julgassem ter sido a primeira leitura prejudicada por nervosismo. Quando todos retornamos à sala, pedi para escreverem um parágrafo dizendo: How did you feel while doing the reading aloud? Como esperado, muitos relataram nervosismo. Mas também surpresa por terem tido uma atenção individual em curso deste tipo e curiosidade por saberem como se saíram. Vou agora voltar a fita com cada um, dando feedback sobre os tópicos para os quais eles se prepararam (acima mencionados). Eles sabiam que isto era só treino e não valia nota. Eles sabiam também que sou adepto de "English as an international language" e que cada um fixa seus objetivos em termos de atingir, ou não, "native-like pronunciation”.(...) [Pedro, correspondência eletrônica]

Lembrando que entendo esta seqüência como representações que o professor faz da turma como um todo e também do que antecipa que a pesquisadora quer ouvir, interpreto nessas imagens, várias marcas que se condensam em atos com o efeito de cooperação entre os sujeitos, nos quais elementos do discurso mais autoritário (científico/técnico) migram para atos de cunho afetivos, isto é, ações lúdicas com o efeito de ocultar as tensões constitutivas das relações sociais. (sempre segundo a representação que o professor fez dos alunos em geral).

Há, porém, um gesto de aproximação do discurso da ciência, na qual a utilização de testes diagnósticos é apontada como um ato de avaliação formativa. No discurso da avaliação formativa, fazem-se registros dos pontos fortes e fracos dos alunos olhando-os como indivíduos (na representação do ensino centrado no aluno). Em conformação com a política do afeto, esse discurso significa 'não apresentar as tensões promovidas por avaliações com notas'. Além disso, a situação social da sala de aula é representada como não competitiva (o aluno só é comparado a si mesmo) e posiciona o professor como compreensivo (ele compreende e acompanha o processo do aluno) e não classificatório (todos podem alcançar um mínimo de proficiência).

Cabe ainda levantar que os atos do professor Pedro se inserem numa modulação desta FD, nomeada Inclusão Incondicional. Nela, todos os alunos progridem incondicionalmente; todos são aprovados. Vejamos a seqüência que se segue à anterior:

14. (...) Next, vou fazer entrevista gravada, focalizando agora conversational analysis: turn-taking, false starts, repetition, self-correction. Pressuposto: Brazilian English is acceptable, mas um mínimo de fluency is expected (para Língua VII). Eles terão tido temas para se prepararem. (...) [Pedro, correspondência eletrônica]

Problematizemos aquele 'mínimo' abstrato ao qual se refere o professor ao dizer: 'Brazilian English is acceptable, mas um mínimo de fluency is expected (para o último 
NEVES - Processo discursivo e subjetividade...

nível de LE do curso).' Se o aluno chegou até naquele nível, ou bem ou mal, este é o mínimo do qual partirá. Como os sentidos derivam entre o dito e o não dito dos vários domínios aí fazendo efeito, um critério de um mínimo significa que qualquer coisa que o aluno fizer para sair desse mínimo, ele será recompensado com uma nota acima de zero (já que nenhum zero foi conferido). Este mínimo é, portanto, acima da reprovação, o que nesta conformação se traduziu em notas bem generosas (mínimo de 3 em 5 neste evento) e nenhuma reprovação no final do curso.

\section{CONCLUSÃO}

Como consideração final de um trabalho complexo e que mal pude retratar aqui, retomo a afirmação de que o ato de avaliar é um gesto de interpretação que concorre para produzir e é produzido por FDs. Estas têm fronteiras fluidas, pois estão no frágil âmbito das relações imaginárias, em processos instáveis de identificação. Esses processos são incertos, fluidos, justamente porque somos sujeitos desejantes e também efeito de sentido de uma história, de uma ideologia, que põem em conflito as relações entre sujeitos por mais neutras que pretendam ser.

Afinal não é somente porque o professor conhece a abordagem de ensino e as técnicas de avaliação que suas decisões avaliativas são determinadas, mas sobretudo porque se insere em Formações Discursivas que preponderam em seus atos. Entendo estas como as esquecidas vozes de uma memória discursiva advindas de vários domínios sociais, históricos, e ideológicos - o interdiscurso - e também do inconsciente operando juntamente com a materialidade do dizer que constituem os sujeitos e são constitídas por eles. Num ou noutro momento, o sujeito se posiciona a partir da predominância fluida de um ou de outro domínio assim como também de um desejo que não se dá a ver, mas marca as suas contradições.

\section{REFERÊNCIAS BIBLIOGRÁFICAS}

AUTHIER. J. (1984). Hétérogenéité(s) énonciative(s), Langages, n. 73, p.91-151.

(1998). Palavras incertas: as não-coincidências do dizer. Campinas: Editora da Unicamp.

BAKHTIN, Mikhail. (1992). Estética da criação verbal. São Paulo: Martins Fontes.

BRASIL, (1997). Parâmetros Curriculares Nacionais - Primeiro e segundo ciclos do ensino fundamental. Brasília: MEC/SEF.

(1998). Parâmetros Curriculares Nacionais - Terceiro e quarto ciclos do ensino fundamental. Brasília: MEC/SEF. (1998). Parâmetros Curriculares Nacionais - Ensino Médio. Brasília: MEC/SEF.

CASTELO BRANCO, G. (1995). O olhar e o amor: a ontologia de Lacan. Rio de Janeiro: NAU Editora.

CORACINI, M.J.R.F. (1995). O jogo discursivo na aula de leitura: língua materna e língua estrangeira. Campinas: Pontes.

. (1998). Língua estrangeira e língua materna: uma questão de sujeito e identidade. Letras \& Letras, vol.14, n.1, p. 153-170. 
(2003). O discurso da Lingüística Aplicada e a questão da identidade: entre a modernidade e a pósmodernidade. In: CORACINI, M.J.R.F, BERTOLDO, E.S. O desejo da teoria e a contingência da prática.Campinas: Mercado de Letras, p. 97-115.

COURTINE J.J. (1981). Analyse du discours politique, Langages, n. 62, Paris: Larousse, p. 9-128.

DICKINSON, L. (1987). Self-instruction in language learning. Cambridge: Cambridge University Press.

DUCROT, O. (1987). O dizer e o dito. Campinas: Pontes.

FOUCAULT, M. (1997). A arqueologia do saber. $5^{\text {a }}$. ed., Rio de Janeiro: Forense Universitária.

FREUD, S. (1969). Cinco Lições de Psicanálise. Rio de Janeiro: Imago, (Ed. Eletrônica).

GENESEE, F; UPSHUR, J. A. (1996). Classroom -based evaluation in second language education. Cambridge: Cambridge University Press.

HERMAN, J.L.; ASCHBACHER,P.R.; WINTERS L. (1992). A practical guide to alternative assessment. Alexandria,Va.: Association for Supervision and Curriculum Development.

LACAN, J. (1998). Escritos. Rio de Janeiro: Jorge Zahar Editor.

(1985). O Seminário, livro 3: As psicoses. 2" ed. Rio de Janeiro: Jorge Zahar Editor.

(1985b). O Seminário, livro 11: Os quatro conceitos fundamentais da psicanálise. 2 ed. Rio de Janeiro: Jorge Zahar Editor.

NEVES, M. S. (2002). Processo discursivo e subjetividade: vozes preponderantes na avaliação da oralidade em língua estrangeira no ensino universitário. 276p. Tese (Doutorado em Lingüística Aplicada) Instituto de Estudos da Linguagem, Universidade Estadual de Campinas, Campinas.

(1998). O portfolio na avaliação de aprendizagem de língua estrangeira. $34 \mathrm{f}$. Monografia (Curso de Especialização em Avaliação à Distância). Brasília: Universidade de Brasília.

NUNAN, D. (1989). Designing tasks for the communicative classroom. Cambridge: Cambridge University Press.

O'MALLEY, J. M. CHAMOT, A. U. (1990). Learning strategies in second language acquisition. Cambridge: Cambridge University Press.

O'MALLEY, M.; PIERCE, L. V. (1996). Authentic assessment for English language learners: practical approaches for teachers. New York: Addison-Wesley Publishing Company.

ORLANDI, E. P. ( 1996). A Linguagem e seu funcionamento: as formas do discurso. $4^{\mathrm{a}}$. ed. Campinas: Pontes. (1998). Discurso e argumentação: um observatório do político. Fórum Linguiístico, n.1, p. 73-81. (1998a). Interpretação: autoria, leitura e efeitos do trabalho simbólico. 2a. ed. Petrópolis: Vozes. (1999). Análise de discurso: princípios e procedimentos. Campinas: Pontes.

OXFORD, R. L. (1990). Language learning strategies. Boston: Heinle \& Heinle Publishers.

PÊCHEUX, M. (1990). Análise automática do discurso. In: GADET, F.; HAK,T. (Org.) Por uma análise automática do discurso: uma introdução à obra de Michel Pêcheux. Campinas: Editora da Unicamp, p. $61-161$.

(1995). Semântica e discurso: uma crítica à afirmação do óbvio. $2^{2}$ ed. Campinas: Unicamp. 
PÊCHEUX, M.; FUCHS,C. (1990). A propósito da análise automática do discurso: atualização e perspectivas. In: GADET,F., HAK,T. (Org.) Por Uma análise automática do discurso: uma introdução à obra de Michel Pêcheux. Campinas: Editora da Unicamp. p. 163-246.

PRASSE, J. (1997). O desejo das línguas estrangeiras. Revista Internacional. Rio de Janeiro, Paris, Nova York, Buenos Aires: Companhia de Freud, ano 1, n. 1, p. 63-73.

REID, J. (Org.) (1995). Learning styles in the ESL/EFL classroom. Boston: Newbury House.

RIOLFI, C. R. (1999). O discurso que sustenta a prática pedagógica: formação de professor de língua materna. 361f. Tese (Doutorado em Lingüística). Instituto de Estudos da Linguagem, Universidade Estadual de Campinas, Campinas.

SCARAMUCCI, M.V.R. (1998). Avaliação: mecanismo propulsor de mudanças no ensino - aprendizagem de língua estrangeira. XIV JELI, São José do Rio Preto. Mesa Redonda: A avaliação em sala de aula de língua estrangeira. Trabalho não publicado.

SERRANI-INFANTE, S.M. (1997). Formações discursivas e processos identificatórios na aquisição de línguas. D.E.L.T.A., vol. 13 , n. 1, p. 63-81.

(1998). Abordagem Transdisciplinar da Enunciação em Segunda Língua: a proposta AREDA. In: SIGNORINI, I..; CAVALCANTI, M.C. (Orgs.) Lingüística aplicada e transdisciplinaridade. Campinas: Mercado de Letras. p. 143-167.

. (1999). Discurso e aquisição de segundas línguas: proposta AREDA de abordagem. In: INDURSKY, F.; FERREIRA, C.L. (Org.) Os múltiplos territórios da Análise do discurso. Porto Alegre: Editora Sagra Luzzatto. p. 281-300.

(2001). Resonancias discursivas y cortesía en prácticas de lecto-escritura. D.E.L.T.A.,v. 17, n. 1, p. $31-58$.

VIGOTSKY, L S. (1987). Pensamento e Linguagem. São Paulo: Hucitec. 